\title{
Gambaran Self Efficacy Pada Pasien Diabetes Tipe 2 di Poliklinik Penyakit Dalam RSUPN Dr. Cipto Mangunkusumo Jakarta
}

\author{
Shanty Chloranyta ${ }^{1}$ \\ 1Program Studi DIII Keperawatan \\ Sekolah Tinggi Ilmu Kesehatan Panca Bhakti Bandar Lampung \\ Corresponding author : shanty@pancabhakti.ac.id
}

\begin{abstract}
Self-efficacy is an individual's assessment of the ability to complete a given task. Diabetes self-efficacy is required to improve the outcome of diabetes management. This study aims to assess the ability of self-efficacy in diabetic patients using Diabetes Management Self Efficacy (DMSE). The research design used is descriptive method. The study was conducted at the Internal Medicine Polyclinic of Cipto Mangunkusumo Hospital Jakarta with 60 samples of type 2 diabetes patients using consecutive sampling technique. The measuring instruments used were demographic characteristics and Diabetes Management Self Efficacy (DSME). The results showed the characteristics of the respondents in the study were $57 \%$ women, the highest education was high school respondents (33\%), the most complications were diabetic retinopathy (38\%). Based on the mean age of type 2 diabetes respondents, namely 57.60 years, the average length of diabetes was 11.40 years, and the mean self-efficacy score was 59.0. Assessment of self-efficacy using DMSE can be used to assess self-efficacy in type 2 diabetes, so that it can make it easier for nurses to educate and counsel patients with type 2 diabetes related to self-efficacy so that it can improve selfmanagement in type 2 diabetes patients.
\end{abstract}

Keywords: diabetes type 2, diabetes management self efficacy (DMSE), self-efficacy

\section{PENDAHULUAN}

ADA (2016) menyatakan bahwa diabetes merupakan penyakit kronis yang membutuhkan perawatan yang berkelanjutan serta self management untuk mencegah komplikasi. Self management merupakan bagian integral dari diabetes self management (Boutati \& Raptis, 2009). Self management adalah aktifitas yang kompleks termasuk kemampuan dalam mengontrol suatu kondisi dengan afek kognitif, perilaku dan respon emosional dalam mempertahankan kebutuhan kualitas hidup (Heinrich, Schaper, \& Vries, 2010).

Self management pada diabetes dapat dilakukan dengan melakukan berbagai upaya. Upaya yang dapat dilakukan yakni melalui pengaturan diet, latihan fisik, pengaturan obat-obatan, pengontrolan glukosa darah mandiri dan pemeriksaan kesehatan (Heinrich, Schaper, \& Vries, 2010). Kemampuan pasien diabetes dalam melakukan self management merupakan hal yang penting. 
Akan tetapi selama ini di RSUPN Dr. Ciptomangunkusumo Jakarta perawat belum melakukan pengkajian self management pada pasien diabetes tipe 2. Pengkajian secara komprehensif bertujuan agar perawat dapat menentukan edukasi yang tepat serta untuk meningkatkan keberhasilan dalam pengelolaan diabetes. Bagi pasien, identifikasi kemampuan self management dapat menentukan kebutuhan edukasi karena pasien ikut serta dalam menentukan prioritas masalah kesehatan yang ingin diselesaikan.

Oleh sebab itu, diperlukan adanya pengkajian untuk mengidentifikasi kemampuan pasien dalam melakukan self management. Instrumen yang dapat digunakan untuk mengidentifikasi yakni kuesioner diabetes management self efficacy pada pasien diabetes tipe 2 yakni Diabetes Management Self Efficacy (DMSE). Instrumen DMSE dikembangkan oleh Bijl, Pooelgest-Eetlink (1999). Berdasarkan fenomena yang ditemukan penulis selama melakukan praktik di RSUP Dr.Cipto Mangunkusumo Jakarta, masalah yang dialami oleh pasien diabetes yakni kemampuan dalam melakukan self management. Pengkajian mengenai kemampuan self management yang dilakukan oleh pasien diabetes di rumah belum dilakukan selama ini, sehingga peneliti ingin melakukan pengkajian kemampuan self efficacy pada pasien diabetes DM menggunakan Diabetes Management Self Eficacy (DMSE).

\section{METODE}

Penelitian ini merupakan penelitian kuantitatif dengan desain deskriptif analitik menggunakan pendekatan cross sectional. Populasi dalam penelitian ini yakni pasien yang melakukan kontrol rutin ke Poliklinik Penyakit Dalam RSUPN Dr. Cipto Mangunkusumo Jakarta, dengan jumlah sampel berjumlah 60 responden diabetes tipe 2. Penelitian dilakukan di RSUPN Dr. Cipto Mangunkusumo Jakarta, pada bulan April 2018. Kriteria inklusi yakni pasien diabetes tipe 2 ditunjukkan dengan rekam medis pasien, didapatkan dari informasi dokter spesialis penyakit dalam dan perawat Poliklinik Penyakit Dalam Rumah Sakit Cipto Mangunkusumo Jakarta, dapat berkomunikasi dengan baik, bersedia menjadi responden dalam penelitian ini, berusia $\geq 18$ tahun, pasien yang mampu membaca dan menulis sederhana sedangkan kriteria eksklusi yakni pasien yang tidak melengkapi seluruh item pernyataan yang tercantum dalam kuesioner, pasien yang mengalami kondisi kritis maupun penurunan kesadaran.

Data diambil dengan menggunakan data demografi dan kuesioner Diabetes Management Self Efficacy (DSME). Uji instrumen dilakukan pada 30 pasien diabetes di poliklinik Poliklinik Penyakit Dalam Rumah Sakit Cipto Mangunkusumo. Uji dilakukan dengan menggunakan validitas rupa dan validitas konstruk. Hasil uji kuesioner DSME menggunakan korelasi Pearson Product Moment menunjukkan hasil uji reliabilitas terhadap 20 item pernyataan didapatkan hasil cronbach- $\alpha$ 0,939 sehingga kuesioner dinyatakan reliabel. 
Jurnal Ilmu Keperawatan Medikal Bedah Vol. 3 (2), Bulan November Tahun 2020 , Hal. $42-48$ ISSN 2338-2058 (print), ISSN 2621-2986 (online)

\section{HASIL}

Tabel 1

Distribusi karakteristik responden diabetes tipe 2

di Poliklinik Penyakit Dalam RSUPN Dr. Ciptomangunkusumo Jakarta Bulan April Tahun 2018 (n=60)

\begin{tabular}{clcc}
\hline \multicolumn{1}{c}{ Variabel } & \multicolumn{1}{c}{ Kategori } & Jumlah & Persentase (\%) \\
\hline Jenis Kelamin & Laki-laki & 26 & 43 \\
& Perempuan & 34 & 57 \\
& Tidak Sekolah & 2 & 2 \\
& SD & 11 & 18 \\
& SMP & 10 & 16 \\
& SMA & 20 & 33 \\
& D3 & 6 & 10 \\
Komplikasikan & S1 & 11 & 21 \\
& Tidak ada & 4 & 7 \\
& Hipertensi & 7 & 12 \\
& Gagal Ginjal Kronis & 10 & 17 \\
& Ulkus Diabetik & 5 & 8 \\
& Penyakit Jantung Koroner & 9 & 15 \\
& Stroke & 2 & 3 \\
& Retinopati diabetik & 23 & 38 \\
\hline
\end{tabular}

Berdasarkan tabel 1 karakteristik responden menurut jenis kelamin menunjukkan presentase terbanyak perempuan (57\%), pendidikan tertinggi SMA responden (33\%), dan komplikasi terbanyak retinopati diabetik (38\%).

Tabel 2

Distribusi responden berdasarkan usia, lama diabetes dan self efficacy pada responden diabetes tipe 2 di Poliklinik Penyakit Dalam RSUPN Dr. Cipto Mangunkusumo Jakarta Bulan April Tahun 2018

\begin{tabular}{lcccc}
\hline Variabel & Mean \pm SD & Median & Min-Maks & $95 \%$ CI \\
\hline Usia & $57.60 \pm 4.541$ & 58.00 & $45-62$ & $56.43-58.77$ \\
Lama Diabetes & $11.40 \pm 0.652$ & 12.00 & $3-20$ & $10.09-12.71$ \\
Self Efficacy & $59.07 \pm 1.810$ & 64.00 & $24-76$ & $55.44-62.69$ \\
\hline
\end{tabular}

Berdasarkan tabel 2 rerata usia responden diabetes tipe 2 yakni 57.60 dengan standar deviasai 4.541 tahun dengan usia terendah yakni 45 tahun dan tertinggi 62 tahun. Selain itu juga diyakini 95\% rata-rata usia berada antara 56.43 hingga 58.77. Rerata lama diabetes 11.40 tahun dengan standar deviasi 0.652 tahun. Selain itu juga diyakini 95\% rata-rata lama diabetes berada antara 10.09 hingga 12.71 . Rerata skor self efficacy dengan yakni 59.07 dengan standar deviasi 1.810. Selain itu juga diyakini 95\% rata-rata total skor self efficacy berada antara 55.44 hingga 62.69. 
Jurnal Ilmu Keperawatan Medikal Bedah Vol. 3 (2), Bulan November Tahun 2020 , Hal. 42-48 ISSN 2338-2058 (print), ISSN 2621-2986 (online)

\section{PEMBAHASAN}

Karakteristik responden diabetes tipe 2 dalam penelitian ini berdasarkan rerata usia yakni 57.60 tahun. Hasil penelitian ini menunjukkan bahwa kemungkinan kejadian diabetes dalam penelitian ini disebabkan karena proses penuaan yang terjadi pada tubuh. Penuaan dikaitkan dengan hilangnya fungsi mitokondria secara progresif dalam berbagai bentuk jaringan, termasuk otot rangka (Barzilai et al., 2012). Hasil penelitian yang sesuai dengan penelitian ini dilakukan pada 3.471 subyek penelitian di sebuah studi Offspring Farmingham untuk mengetahui prediksi variasi genetik dalam meningkatkan penyakit diabetes membuktikan 144 pasien diabetes berusia $<50$ tahun dan 302 pasien berusia $\geq$ 50 tahun (Miguel-Yanes et al., 2011). Selain itu, usia yang bertambah meningkatkan berbagai perubahan pada komposisi lemak tubuh. Komposisi lemak subkutan menurun, sedangkan lemak pada organ visceral meningkat (lemak di dalam rongga perut). Peningkatan lemak pada organ visceral yang tidak proporsional dibandingkan dengan lemak subkutan menyebabkan distribusi lemak yang tidak merata. Selain itu, gangguan pada tubuh akibat proses penuaan yakni kelemahan dapat menyebabkan berkurangnya mobilitas sehingga terjadi pengurangan pengeluaran energi dan insulin

Hasil analisis menunjukkan persentase terbesar dengan jenis kelamin perempuan sebanyak 34 responden (57 \%) dan 26 responden (43\%) berjenis kelamin laki-laki. Hasil penelitian ini menunjukkan kejadian diabetes terjadi lebih banyak pada perempuan dengan usia lebih dari 45 tahun. Hal tersebut kemungkinan dapat disebabkan oleh perubahan hormonal yang terjadi akibat proses penuaan sehingga mengakibatkan resiko lebih tinggi terjadi diabetes lebih tinggi pada perempuan dibandingkan dengan laki-laki. Perempuan dengan diabetes tipe 2 mengalami perubahan hormonal akibat proses penuaan. Perubahan yang terjadi yaitu penurunan fungsi endokrin akibat proses penuaan. Perubahan pada sekresi growth hormon menurun seiring bertambahnya usia, mengakibatkan penurunan konsentrasi IGF-1 secara bersamaan (Barzilai et al., 2012).

Penelitian lainnya, juga menunjukkan bahwa kejadian diabetes pada perempuan lebih tinggi dibandingkan dengan laki-laki. Hasil penelitian yang dilakukan untuk menganalisa diabetes dan faktor resiko yang berhubungan dengan perempuan dan lakilaki pada 1.503 responden di India menunjukkan $16.7 \%$ diabetes tipe 2 berjenis kelamin perempuan dan 9.7 \% laki-laki (Scavini et al., 2003). Hasil penelitian lain yang juga sesuai dengan penelitian ini dilakukan di 18 rumah sakit dan pusat kesehatan di Jordania Selatan, Utara dan Tengah pada 1.079 responden menunjukkan $53 \%$ responden berjenis kelamin laki-laki dan 47 \% perempuan (Al-keilani, Almomani, Al-sawalha, \& Shhabat, 2017).

Demikian halnya, menurut data diabetes di Indonesia berdasarkan data Riskesdas (2013) menunjukkan lebih tinggi pada perempuan dibandingkan pada laki-laki. Kejadian diabetes pada laki-laki $1.4 \%$ dan perempuan $1.7 \%$. Kondisi gestational diabetes dapat berperan dalam prevalensi perempuan dengan diabetes, perempuan dengan gestational diabetes beresiko $20-50 \%$ mengalami diabetes tipe 2 pada 5 sampai 10 tahun kemudian (Jones, 2013). Penelitian lain yang sesuai dengan penelitian ini untuk menginvestigasi prevalensi dan insidensi kondisi geriatrik pada orang dewasa dan usia lanjut dengan diabetes menunjukkan 3.506 responden terbanyak perempuan yakni 1.811 responden (51.66 \%) (Cigolle et al., 2010). 
Jurnal Ilmu Keperawatan Medikal Bedah Vol. 3 (2), Bulan November Tahun 2020 , Hal. 42-48 ISSN 2338-2058 (print), ISSN 2621-2986 (online)

Berdasarkan pendidikan tertinggi responden dalam penelitian ini yakni SMA 20 responden (33\%), SD 11 responden (18\%), S1 11 responden (21\%), SMP 10 responden (16\%), D3 6 responden (10\%), tidak sekolah 2 responden (2\%). Berdasarkan rerata lama diabetes yakni 11.40 tahun. Selain itu juga diyakini 95\% rata-rata lama diabetes berada antara 10.09 hingga 12.71. Hasil analisis menunjukkan komplikasi terbanyak yaitu retinopati diabetik pada 23 responden (38\%), gagal ginjal kornis 10 responden (17\%), penyakit jantung coroner 9 responden (15\%), hipertensi 7 repoden (12\%), ulkus diabetik 5 repsonden (8\%), stroke 2 responden (3\%), dan tidak ada komplikasi 21 responden (41.2 $\%)$. Faktor yang diduga berkontribusi terhadap komplikasi pada diabetes yaitu lama menderita diabetes.

Hasil penelitian ini didukung oleh penelitian yang dilakukan oleh United Kingdom Prospective Diabetes Study (UKPDS) dari 5.102 partisipan setelah dilakukan follow up selama 25 tahun pasien mengalami komplikasi setelah didiagnosis diabetes. Hasil penelitian UPKDS membuktikan kematian pada 2.260 pasien, serangan miokard infark pertama 1.014 pasien, dan yang kedua 169 pasien, gagal jantung kongestif pada 351 pasien, serta ischemic heart disease 749 pasien. Gangguan yang terjadi pada pembuluh darah meningkatkan serangan stroke berulang. Serangan stroke pertama terjadi pada 504 pasien dan serangan stroke kedua 78 pasien. Komplikasi mikrovaskuler yang terjadi yaitu kebutaan 271 pasien, gagal ginjal 113 pasien, amputasi 171 dan ulkus 97 pasien (Hayes, Leal, Gray, Holman, \& Clarke, 2013).

Berdasarkan self efficacy yang diukur dengan menggunakan DMSE didapatkan rerata yakni 59.07 dengan standar deviasi 1.810. Selain itu juga diyakini 95\% rata-rata total skor self efficacy berada antara 55.44 hingga 62.69. Hasil penelitian ini menunjukkan bahwa self efficacy pada pasien diabetes tipe dapat dipengaruhi oleh keyakinan pasien dalam melakukan manajemen diabetes. Manajemen diabetes memerlukan kebulatan tekad dan keyakinan pasien. Keyakinan menjadi komponen penting dan utama dalam menentukan keberhasilan terapi. Health belief model (HBM) merupakan kerangka konsep yang digunakan untuk menjelaskan pencapaian perubahan perilaku yang optimal. Perubahan perilaku dapat terjadi apabila individu berhasil mengatasi hambatan yang dirasakan, merasakan manfaat, selfefficacy, dan mengatasi ancaman (Jones et al., 2015).

Penelitian lainnya yang juga mendukung yakni meta analisis pada 48 artikel penelitian yang melakukan penilaian untuk mengukur keyakinan, persepsi dan pengetahuan tentang diabetes serta hubungan diantara faktor yang mempengaruhi pengetahuan atau kepatuhan dan tingkat kadar glukosa darah membuktikan keyakinan signifikan dengan kepatuhan untuk meningkatkan self efficacy. Pasien yang patuh lebih percaya diri untuk melaksanakan pengelolaan diabetes dan memiliki konsekuensi positif serta merasakan hubungan yang lebih positif dengan penyedia layanan kesehatan (Gherman et al., 2011).

Demikian halnya, salah satu hasil meta analisis pada 18 artikel penelitian yang dilakukan pada 2.072 sampel penelitian dengan tujuan untuk mengukur keyakinan untuk memprediksi tingkah laku membuktikan keyakinan pasien terhadap tingkat keparahan penyakit dan pengobatan signifikan terhadap tingkah laku pasien dalam melakukan pengelolaan diabetes. Keyakinan pasien tentang tingkat keparahan penyakit dan pengobatan menunjukkan pada pasien yang yakin bahwa dirinya memiliki sakit yang parah maka pasien akan memilih untuk mengkonsumsi obat dibandingkan dengan melakukan pengelolaan diabetes lainnya (Carpenter, 2010). 
Jurnal Ilmu Keperawatan Medikal Bedah Vol. 3 (2), Bulan November Tahun 2020 , Hal. 42-48 ISSN 2338-2058 (print), ISSN 2621-2986 (online)

Self efficacy merupakan komponen utama dalam teori sosial kognitif. Teori ini dikembangkan berdasarkan teori sosial kognitif dan konsep mengenai manusia-perilakulingkungan sebagai suatu sistem yang saling berinteraksi dan memiliki hubungan timbal balik. Bandura mengungkapkan self efficacy merupakan keyakinan individu mengenai kemampuan yang dimiliki untuk melakukan suatu hal ketika berada dalam berbagai macam kondisi dengan ketrampilan yang dimiliki saat ini. Individu membutuhkan skill dan self efficacy dalam mewujudkan perilaku yang ingin dicapai (Peterson \& Bedrow, 2013). Komponen self efficacy meliputi ekspektasi self efficacy dan ekspektasi akan hasil. Ekspektasi self efficacy adalah penilaian tentang kemampuan individu dalam menyelesaikan tugas yang diberikan, sedangkan ekspektasi akan hasil merupakan penilaian tentang apa yang akan terjadi apabila individu sukses dalam menyelesaikan tugas yang diberikan.

Self efficacy dan ekspektasi akan hasil dibedakan karena seorang individu dapat percaya bahwa perilaku tertentu akan menghasilkan suatu hasil spesifik yang diharapkan, namun individu tersebut belum tentu yakin bahwa ia dapat melakukan perilaku tersebut (Peterson \& Bedrow, 2013). Self efficacy mengarahkan pada penilaian individu akan kemampuannya. Individu dengan self efficacy yang tinggi akan lebih gigih, terus berusaha dan berupaya dalam mencapai tujuan. Kemampuan seorang individu dalam melakukan suatu tugas tidak serta merta dapat meningkatkan self efficacy, namun dipengaruhi juga oleh kesuksesan dan kegagalan yang dialami, persepsi terhadap tingkat kesulitan, usaha yang dilakukan dalam mencapai tujuan, pengalaman yang diingat dan diproses oleh daya ingat serta adanya bantuan eksternal dari lingkungan (Bandura 1994; Peterson \& Bredow, 2013).

\section{SIMPULAN}

Hasil penelitian menunjukkan karakteristik responden dalam penelitian yakni perempuan $57 \%$, pendidikan tertinggi SMA responden (33\%), komplikasi terbanyak retinopati diabetik (38\%). Berdasarkan rerata usia responden diabetes tipe 2 yakni 57.60 tahun, rerata lama diabetes 11.40 tahun, dan rerata skor self efficacy yakni 59.07Pengkajian self efficacy dengan menggunakan DMSE dapat digunakan untuk menilai self efficacy pada diabetes tipe 2, sehingga dapat memudahkan perawat dalam upaya edukasi dan konseling pada pasien DM tipe 2 berkaitan dengan self efficacy sehingga dapat meningkatkan self management pada pasien DM tipe 2. 
Jurnal Ilmu Keperawatan Medikal Bedah Vol. 3 (2), Bulan November Tahun 2020 , Hal. 42-48

ISSN 2338-2058 (print), ISSN 2621-2986 (online)

\section{REFERENSI}

American Diabetes Association. (2016). Sandards of medical care in diabetes-2016. The Journal of Clinical and Applied Research and Education, 39(January).

Al-keilani, M. S., Almomani, B. A., Al-sawalha, N. A., \& Shhabat, B. A. (2017). Self monitoring of blood glucose among patients with diabetes in Jordan: perception, adherence, and influential factors. Diabetes Research and Clinical Practice. http://doi.org/10.1016/j.diabres.2017.01.005

Barzilai, N., Huffman, D. M., Muzumdar, R. H., \& Bartke, A. (2012). The critical role of metabolic pathways in aging. Diabetes, 61, 1315-1322. http://doi.org/10.2337/db11$\underline{1300}$

Boutati, E. I., \& Raptis, S. A. (2009). Self monitoring of blood glucose as part of the integral care of type 2 diabetes. Diabetes Care, 32(2), 205-210. http://doi.org/10.2337/dc09$\underline{\mathrm{S} 312}$

Carpenter, C. J. (2010). A Meta analysis of the effectiveness of health belief model variables in predicting behavior. Health Communication, 25(8), 661-669. http://doi.org/10.1080/10410236.2010.521906

Cigolle, C. T., Lee, P. G., Langa, K. M., Lee, Y., Tian, Z., \& Blaum, C. S. (2010). Geriatric conditions develop in middle aged adults with diabetes. Journal General Internal Medicine, 26(3), 272-279. http://doi.org/10.1007/s11606-010-1510-y

Gherman, A., Schnur, J., Montgomery, G., Sassu, R., Veresiu, I., \& David, D. (2011). How are adherent people more likely to think? The Diabetes Educator, 37(3), 392-408. http://doi.org/10.1177/0145721711403012

Hayes, A. J., Leal, J., Gray, A. M., Holman, R. R., \& Clarke, P. M. (2013). UKPDS outcomes model 2 : a new version of a model to simulate lifetime health outcomes of patients with type 2 diabetes mellitus using data from the 30 year United Kingdom Prospective Diabetes Study: UKPDS 82 Lipids in Diabetes Study. Diabetologia, 56, 1925-1933. http://doi.org/10.1007/s00125-013-2940-y

Heinrich, E., Schaper, N. C., \& Vries, N. K. De. (2010). Self-management interventions for type 2 diabetes : a systematic review. EDN Autumn, $7(2)$.

Jones, C. L., Jensen, J. D., Scherr, C. L., Brown, N. R., Christy, K., \& Weaver, J. (2015). The health belief model as an explanatory framework in communication research: exploring parallel, serial, and moderated mediation. Health Communication, 30(6), 566-576. http://doi.org/10.1080/10410236.2013.873363.

Jones, C. J., Smith, H., \& Llewellyn, C. (2013). Evaluating the effectiveness of health belief model interventions in improving adherence : a systematic review. Health Psychology Review, 8(3), 253-269. http://doi.org/10.1080/17437199.2013.802623

Kwon, S. K. (2014). Women are diagnosed with type 2 diabetes at higher body mass indices and older ages than men : Korea National Health and Nutrition Examination Survey. Diabetes and Metabolism Journal, 38, 74-80. http://doi.org/10.4093/dmj.2014.38.1.74

Miguel-Yanes, D., Jose, M., Shrader, P., Pencina, M. J., Fox, C. S., Manning, A. K., ... Dupuis, J. (2011). Genetic risk reclassification for type 2 diabetes by age below or above 50 years using 40 type 2 diabetes risk single nucleotide polymorphism. Diabetes Care, 34, 121125. http://doi.org/10.2337/dc10-1265

Scavini, M., Stidley, C. A., Shah, V. O., Narva, A. S., Tentorini, F., Kessler, D. S., ... Zager, P. G. (2003). Prevalence of diabetes is higher among female than male Zuni Indians. Diabetes Care, 26(1), 55-60. 